\title{
Uso de CRISPR-Cas em plasmídeos conjugativos para o controle da disseminação de resistência a
} antibióticos em Enterococcus: uma revisão de literatura.

Use of CRISPR-Cas in conjugative plasmids to control the spread of antibiotic resistance in

Enterococcus: a literature review.

Uso de CRISPR-Cas en plásmidos conjugativos para controlar la propagación de la resistencia a los antibióticos en Enterococcus: una revisión de la literatura.

Recebido: 26/01/2022 | Revisado: 04/02/2022 | Aceito: 09/02/2022 | Publicado: 14/02/2022

Elias El-Shaddai dos Santos Nery Nunes Ribeiro ORCID: https://orcid.org/0000-0002-4591-5453

Universidade de Brasília, Brasil

E-mail: eliaselshaddai@gmail.com

Joel Antonio Cordeiro de Abreu

ORCID: https://orcid.org/0000-0002-5969-0806

Universidade de Brasília, Brasil

E-mail: joelabreu1993@gmail.com

Fabiana Brandão

ORCID: https://orcid.org/0000-0001-8358-8062

Universidade de Brasília, Brasil

E-mail: fabianabrandao@unb.br

\begin{abstract}
Resumo
Justificativa: Há um forte apelo mundial para controle do uso de antimicrobianos associado a novas abordagens terapêuticas contra infecções multirresistentes, como as ocasionados pelas espécies E. faecalis e E. faecium, patógenos oportunistas comensais normalmente presentes em infecções relacionadas à assistência à saúde (IRAS). A elevada capacidade de adaptação desses patógenos ao ambiente nosocomial e a aquisição de genes de resistência e virulência estão entre os principais fatores que contribuem para o agravo dessas infecções. CRISPR-Cas atua como um sistema de defesa bacteriano, selecionado evolutivamente devido à associação de bactérias com vírus, presente em algumas linhagens de E. faecalis e E. faecium. Especula-se que CRISPR-Cas poderiam ser empregados em diferentes vetores, inclusive plasmídeos conjugativos, para edição e inativação de genes de resistência. Objetivos: Investigar o uso de CRISPR-Cas em plasmídeos conjugativos como controle de disseminação de linhagens enterocócicas multirresistentes. Metodologia: Trata-se de revisão baseada em escopo, aplicando critérios de seleção e inclusão de estudos, no intervalo temporal entre 2016 a 2021. Resultados e Considerações finais: Ferramentas de edição molecular, como CRISPR-Cas, podem ser promissoras alternativas no controle de infecções multirresistentes e contribuir no controle de disseminação hospitalar. As linhagens que não apresentam este sistema são mais susceptíveis a aquisição de elementos genéticos móveis, adquirindo genes de resistência e virulência. A aplicabilidade de CRISPR-Cas em plasmídeos conjugativos é um método inovador e factível, capaz de interferir na aquisição de elementos genéticos móveis, e consequentemente, a redução de genes de resistência e virulência, tanto no gênero Enterococcus quanto em outros gêneros.
\end{abstract}

Palavras-chave: Sistema CRISPR-Cas; Plasmídeo conjugativo; Resistência antimicrobiana; Enterococcus.

\begin{abstract}
Justification: There is a solid worldwide call to control the use of antimicrobials associated with new therapeutic approaches against multidrug-resistant infections, such as those caused by the species E. faecalis and E. faecium, commensal opportunistic pathogens usually present in healthcare-related infections (HAI). The high adaptability of these pathogens to the nosocomial environment and the acquisition of resistance and virulence genes are among the main factors contributing to the worsening of these infections. CRISPR-Cas acts as a bacterial defense system, evolutionarily selected due to the association of bacteria with viruses, present in some strains of E. faecalis and E. faecium. It is speculated that CRISPR-Cas could be used in different vectors, including conjugative plasmids, for editing and inactivating resistance genes. Goals: To investigate the use of CRISPR-Cas in conjugative plasmids to control the spread of multidrug-resistant enterococcal strains. Methodology: This is a scope-based review, applying selection criteria and inclusion of studies in the time interval between 2016 and 2021. Conclusion: Molecular editing tools, such as CRISPR-Cas, may be promising alternatives in controlling multidrug-resistant infections and contribute to the control of hospital spread. Strains that do not have this system are more susceptible to acquiring mobile genetic elements, acquiring resistance and virulence genes. The applicability of CRISPR-Cas in conjugative
\end{abstract}


plasmids is an innovative and feasible method, capable of interfering in the mobile genetic elements acquisition, and consequently, reducing resistance and virulence expression, both in the Enterococcus genus and in others.

Keywords: CRISPR-Cas system; Conjugative plasmid; Antimicrobial resistance; Enterococcus.

\section{Resumen}

Justificación: Existe un sólido llamado a nivel mundial para controlar el uso de antimicrobianos asociado con nuevos enfoques terapéuticos contra infecciones multirresistentes, como las causadas por las especies E. faecalis y E. faecium, patógenos comensales oportunistas generalmente presentes en infecciones relacionadas con la atención de la salud. (HAI). La alta adaptabilidad de estos patógenos al ambiente nosocomial y la adquisición de genes de resistencia y virulencia se encuentran entre los principales factores que contribuyen al empeoramiento de estas infecciones. CRISPR-Cas actúa como un sistema de defensa bacteriano, seleccionado evolutivamente debido a la asociación de bacterias con virus, presente en algunas cepas de E. faecalis y E. faecium. Se especula que CRISPRCas podría usarse en diferentes vectores, incluidos plásmidos conjugativos, para editar e inactivar genes de resistencia. Objetivos: investigar el uso de CRISPR-Cas en plásmidos conjugativos para controlar la propagación de cepas de enterococos multirresistentes. Metodología: Esta es una revisión basada en el alcance, aplicando criterios de selección e inclusión de estudios en el intervalo de tiempo entre 2016 y 2021. Conclusión: Las herramientas de edición molecular, como CRISPR-Cas, pueden ser alternativas prometedoras en el control de infecciones multirresistentes y contribuir al control de la propagación hospitalaria. Las cepas que no cuentan con este sistema son más susceptibles de adquirir elementos genéticos móviles, adquiriendo genes de resistencia y virulencia. La aplicabilidad de CRISPR-Cas en plásmidos conjugativos es un método innovador y factible, capaz de interferir en la adquisición de elementos genéticos móviles, y en consecuencia, reducir la expresión de resistencia y virulencia, tanto en el género Enterococcus como en otros.

Palabras clave: Sistema CRISPR-Cas; Plásmido conjugativo; Resistencia antimicrobiana; Enterococcus.

\section{Introdução}

O gênero bacteriano Enterococcus começou a ser descrito no final do século XIX, mais precisamente em 1899. Este gênero é caracterizado por se apresentar como cocos Gram-positivos de origem intestinal, saprofíticos e comensais oportunistas. Dentre as espécies deste gênero, Enterococcus faecium e Enterococcus faecalis destacam-se por apresentar um elevado grau de resistência a antibióticos, podendo estar associadas a infecções relacionadas à assistência à saúde (IRAS) (Gilmore, et al., 2014). E. faecalis é um dos patógenos mais comumente presente em amostras de endocardites infecciosas de pacientes portadores de HIV, usuários de dispositivos de ressincronização cardíaca, indivíduos que realizam diálises, também em casos de infecções cruzadas (infecções relacionadas à assistência à saúde), em abscessos epidurais e em pacientes imunocomprometidos (não-HIV) (Vogkou, et al., 2016). Em países do Sudoeste Asiático e Mediterrâneo oriental, E. faecalis apresenta uma taxa crescente de prevalência de resistência à Vancomicina e a fluoroquinolonas (Shiadeh, et al., 2019).

Com relação a E. faecium, há relatados de aumento significativo da prevalência da resistência a Vancomicina na Turquia, África, Etiópia, Nigéria (Kilbas et al., 2018; Alemayehu et al., 2020; Melese, et al., 2020; Wada, et al., 2020). Além disso, essa mesma tendência de aumento da resistência aos antibióticos, tem sido vista em outros estudos que apontam o aumento da prevalência da resistência aos aminoglicosídeos, tanto em E. faecium quanto em E. faecalis, no Irã e até mesmo no Brasil (Peyvasti, et al., 2020; Jannati et al., 2020; Bender, et al., 2009).

A capacidade adaptativa dessas espécies ao ambiente nosocomial, associado à aquisição de genes de resistência e virulência, configura um problema de saúde pública alarmante. Somado a isso, a Organização mundial de saúde vem emitindo alertas acerca da necessidade do uso racional de antimicrobianos e controle de linhagens multirresistentes (Centers for Disease Control and Prevention, 2019).

Neste contexto, torna-se imperativo o desenvolvimento de abordagens para controle da disseminação de Enterococos multirresistentes. A busca por novos métodos prioriza a redução dos impactos da seleção natural de linhagens resistentes, ocasionados por uso empírico de antibióticos. No âmbito da pesquisa clínica, abordagens terapêuticas para a mitigação do problema da resistência a antibióticos, preservando a microbiota intestinal, são foco de estudos. 


\subsection{Antibióticos de próxima geração}

De la Fuente, et al. (2017) sumariza algumas das novas alternativas denominadas "antibióticos de próxima geração", agrupando-os em dois sistemas: sistemas baseados em peptídeos e sistemas baseados em ácidos nucleicos.

Os sistemas baseados em peptídeos albergam as seguintes classes de medicamentos: Peptídeos sintéticos e Lisinas. Os peptídeos sintéticos são projetados por engenharia de peptídeos para possuir especificidade a determinada espécie bacteriana, visando a toxicidade seletiva contra elas. Em estudos recentes, têm-se demonstrado que o peptídeo sintético produzido a partir da bacteriocina EntV oriunda de E.faecalis pode inibir a morfogênese hifal e a formação de biofilme em Candida albicans, mostrando assim, que essa nova modalidade de antibióticos podem ser útil para depleção da virulência em C.auris, impedindo que a mesma se dissemine (Graham, et al., 2017). As Lisinas, no que lhe concerne, são enzimas hidrolíticas oriundas de bacteriófagos capazes de quebrar a parede celular bacteriana ao término do ciclo lítico do bacteriófago, sendo a PlyV 12 um exemplo de lisina eficaz no controle da disseminação de E.faecalis e E.faecium (Yoong, et al., 2004).

Por outro lado, os sistemas baseados em ácidos nucleicos também têm sido amplamente explorados e esse sistema alberga as seguintes classes: Ácidos Nucleicos peptídicos (PNAs), Morfolino-oligômeros de fosforodiamidato (PMOs) e sistemas CRISPR-Cas. Os Ácidos Nucleicos peptídicos (PNAs) são polímeros sintéticos compostos por unidades repetidas de N-(2aminoetil) -glicina associados as bases purinas e pirimidinas, ligadas entre si mediante ligações petídicas. Os PNAs são fármacos "antisenses", que no momento da tradução interrompem o processamento de determinados genes alvos ligando-se ou ao mRNA ou ao ribossomo bacteriano (Wojciechowska, et al., 2020). Morfolino-oligômeros de fofosforodiamidato (PMOs) são oligômeros sintéticos compostos pelas mesmas quatro bases nitrogenadas do DNA humano e animal, porém, com algumas alterações em sua estrutura química, impedindo que o mesmo efetue ligação fosfato, também são solúveis em água, quase neutros em cargas e resistentes a nucleases. Os PMOS são antimicrobianos anti-sentido, ou seja, oligonucleotídeos cuja sequência complementar de Morfolino e fosforamidato sintéticos pode ser transcrito e traduzido pela própria bactéria que o recebe, gerando

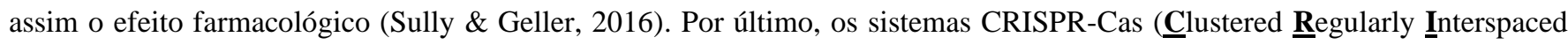

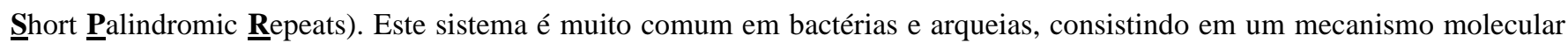
similar ao sistema imunológico adaptativo, destinado a proteger a célula bacteriana da invasão de patógenos, como vírus e plasmídeos infecciosos. Visto que CRISPR-Cas atua na deleção de genes específicos, ele tem sido amplamente estudado na tentativa de possibilitar edição genes guiada.

CRISPR-Cas podem ser empregados como "tesouras" precisas na inativação de genes de resistência e virulência específicos, por exemplo, mediante a utilização de vetores que carreiam consigo o sistema CRISPR-Cas, tanto em bateriófagos quanto em plasmídeos (Gholizadeh, et al., 2020). A utilização de plasmídeos conjugativos contendo sistemas CRISPR-Cas já foi utilizada em outros gêneros bacterianos, tal como um estudo recente em Escherichia coli, em que pesquisadores objetivaram deletar o gene $m c r-1$ de resistência à colistina. Surpreendentemente, notou-se que o uso de plasmídeos contendo CRISPR-Cas9 diminuiu em 62 vezes a ocorrência da transferência do gene $m c r-1$ (Dong, et al., 2019).

Estudos semelhantes foram realizados com outras cepas de E. coli, contudo, alvejando o gene de resistência a antibióticos

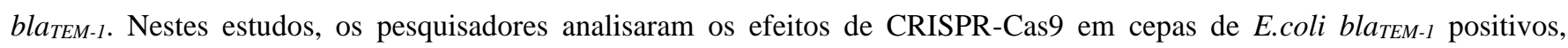
abrigados no plasmídeo pSB1A2, um plasmídeo de alta frequência de cópias. Os resultados, interessantemente, demonstraram que o método conseguiu reduzir a expressão do gene bla $a_{T E M-1}$, diminuindo a expressão de B-lactamases (Tagliaferri, et al., 2020). Ainda em outros estudos, pesquisadores empregaram capsídeos de bacteriófagos abrigando CRISPR-Cas13a direccionados contra genes de resistência a carbapenêmicos em E.coli e genes de resistência a meticilina em Staphylococcus aureus, notando-se que houve sensibilização dessas bactérias (Kiga, et al., 2020).

Em consonância com esses resultados supracitados, a utilização de CRISPR-Cas9 também atuou na reversão da resistência a carbapenêmicos em Shewanella algae (um patógeno marinho emergente) possibilitando a edição do genoma deste 
organismo, com foco nos genes sul2, bla OXA-55- like e $N m c R$ cujos próprios pesquisadores identificaram como sendo os prováveis genes responsáveis pela resistência a carbapenêmicos em Shewanella algae. Conforme o esperado, as cepas nocaute para os genes sul 2 e bla OXA-55-like apresentaram diminuição da resistência a sulfonamidas, ampicilina e imipenem(Wu, et al., 2019).

Portanto, corrobora-se que o sistema CRISPR-Cas têm sido testado em diferentes espécies e gêneros bacterianos nos quais se tem obtido resultados animadores. Tais achados fundamentam a hipótese de se alcancar sucesso frente ao uso de CRISPR-Cas em sistemas conjugativos como uma nova forma de controle da disseminação de genes de resistência a antibióticos. Diante disto, o objetivo do presente trabalho foi analisar, junto a literatura científica, estudos experimentais que utilizaram vetores plasmidiais contendo sistemas CRISPR-Cas em bactérias enterocócicas, com o intuito de depletar genes de resistência e virulência e estimar seu potencial de aplicação para o controle da disseminação de tais genes entre as espécies do gênero Enterococcus.

\section{Metodologia}

Trata-se de uma revisão escopo, de caráter descritivo e discursivo, acerca do uso de sistemas CRISPR-Cas em plasmídeos conjugativos, para depletar genes de resistência e virulência em Enterococcus spp. Foram realizadas buscas por trabalhos científicos durante o período 2016 a 2021, nas seguintes bases de dados: National Library of Medicine (PUBMED), Science Direct e Scopus, valendo-se dos seguintes descritores: CRISPR-Cas system, Conjugative plasmid, antimicrobial resistance e Enterococcus. Todos os descritores utilizados seguiram segundo os termos MESH (Medical Subject Heading).

O processo de seleção de artigos para análise se deu em três etapas: triagem, seleção e inclusão.

\section{a) Triagem}

O processo de triagem consistiu na simples aplicação das palavras-chave com o operador booleano "AND" entre cada descritor nos mecanismos de busca avançada das plataformas de indexação de artigos científicos supracitados. Os únicos critérios de elegibilidade considerados nesta etapa foram: o tempo de pesquisa do presente estudo (2016 - 2021) e, no caso das plataformas ScienceDirect e Scopus, busca limitada apenas a artigos experimentais (article) e revisões de literatura (review), valendo-se de mecanismo de seleção de categorias de estudos destas plataformas, o mesmo não foi possível de ser realizado na plataforma PubMed. Todos os artigos duplicados foram automaticamente excluídos após a triagem. O objetivo da triagem foi obter um conjunto de dados potencialmente elegíveis para análise.

\section{b) Seleção}

Nesta etapa, o objetivo foi reduzir o número de artigos para se obter um conjunto de dados tangíveis e específicos para o objetivo geral da pesquisa. Para se alcançar tal intento, foram utilizados critérios de inclusão e exclusão. Nem todos os artigos considerados como "não-elegíveis" para análise foram descartados, alguns foram realocados na introdução do presente estudo.

\section{1- Critérios de inclusão:}

Artigos de revisão de literatura que versem sobre CRISPR e suas possíveis aplicações para uso terapêutico;

Artigos de revisão de literatura ou experimentais que buscam elucidar o perfil imunitário de bactérias do gênero Enterococcus frente a ambientes adversos;

Artigos experimentais que falem especificamente do uso de CRISPR-Cas em plasmídeos direcionados contra bactérias do gênero Enterococcus. 


\section{2- Critérios de exclusão:}

Artigos, tanto de revisão de literatura quanto experimentais que versam sobre CRISPR-Cas, porém, com objetivos diversos ao do presente estudo;

Artigos experimentais que versam sobre o uso de CRISPR-Cas para fins terapêuticos, porém, em espécies que não pertencem ao gênero Enterococcus;

Artigos experimentais que versem sobre o uso de CRISPR-Cas para uso terapêutico, em espécies do gênero Enterococcus, porém, em vetores não plasmidiais.

\section{c) Inclusão}

Por fim, a etapa de Inclusão. A fase de inclusão, no que lhe concerne, tem como fim o estabelecimento de uma base de dados tangíveis composta por todos os artigos elegidos para análise e discussão dos resultados com a finalidade de corroborar para o objetivo geral do presente estudo.

Fluxograma 1 - Esquema demonstrando o desenvolvimento dos processos de análises dos critérios estipulados para estudo: triagem, seleção e inclusão.

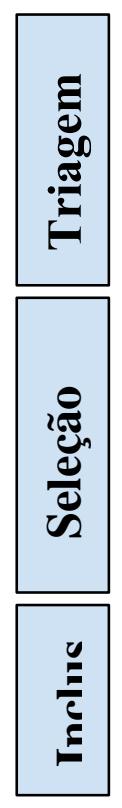

$\mathrm{n}^{\mathrm{a}}$ de estudos obtidos: 179

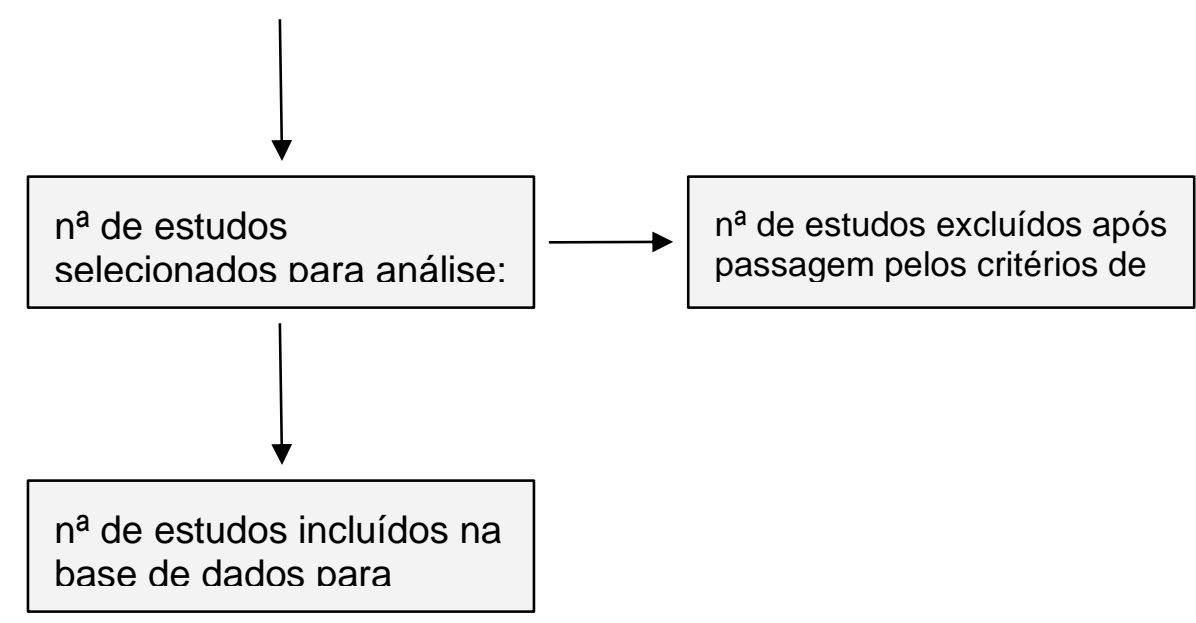

Fonte: Autores.

Eventualmente, artigos fora do intervalo de tempo da pesquisa foram analisados e discutidos, de modo a dar suporte aos dados atuais e permitir enriquecimento de informações.

Inicialmente, os trabalhos foram selecionados com base nos descritores. Na sequência, foi realizada leitura exploratória e seletiva dos materiais, seguida de inclusão de estudos que contemplasse o objetivo desta revisão.

Por fim, os estudos incluídos passaram por revisão crítica e leitura interpretativa para a redação desta revisão. 


\section{Resultados e Discussão}

\subsection{CRISPR-Cas9 - mecanismo de ação e possíveis vetores de entrega para uso terapêutico.}

CRISPR (Clustered Regularly Interspaced Short Palindromic Repeats) de forma geral e em uma comparação extrapolativa, atua como o sistema imunológico adaptativo de mamíferos, porém, presente em bactérias e arqueias (Ahme, et al., 2018). A nomenclatura deste sistema se deve a sua morfologia característica: uma matriz de sequências genéticas repetidas inter-espaçadas por pequenas sequências de DNA denominadas “espaçadores”. O locus CRISPR-Cas9 é constituído pelos seguintes componentes: matriz CRISPR (sequências repetidas e espaçadores) e a nuclease Cas9, proteína de assinatura dos sistemas CRISPR-Cas do tipo II, presente em E.faecalis.

O mecanismo de ação do sistema CRISPR-Cas se dá em três fases: 1- adaptação, 2- expressão e 3- Interferência. Na fase de adaptação, parte da sequência genética de plasmídeos e DNAs invasores são armazenadas no material genético do procarioto, em uma região denominada espaçadores, criando assim um tipo de memória genética que serve para a detecção específica de invasores semelhantes num segundo encontro. Posteriormente, em um segundo momento ocorre a fase de expressão, dividida em duas etapas: expressão do pré-crRNA e maturação da matriz CRISPR recém expressa. Na primeira etapa, o pré-crRNA é totalmente expresso, tanto os espaçadores quanto a proteína $\operatorname{Cas} 9$, contudo ainda permanecem presos a matriz. Na segunda etapa, os espaçadores são destacados da matriz, tornando-se gRNAs (guide RNas) ou crRNAs (RNA CRISPR) maduros. Após isto, o crRNA maduro interage com tracrRNA, uma sequência de RNA adicional que auxilia na montagem do sistema, que guia a clivagem mediada por Cas 9 . Por fim, a fase de interferência, onde vale ressaltar que esta fase se desenrola no momento em que a célula bacteriana está em risco, frente a plasmídeos invasores, consistindo no funcionamento do sistema CRISPR-Cas reconhecendo as sequências alvos invasoras por complementaridade de bases e promovendo a degradação do DNA invasor (Gupta, et al., 2019).

Quanto ao modo de entrega do sistema CRISPR-Cas9, têm-se descrito normalmente na literatura quatro maneiras: Plasmídeos conjugativos, nanopartículas baseadas em polímeros que entregam complexos de ribonucleoproteína Cas9-sgRNA, fagomídeo e o uso de CRISPR-Cas no genoma de fagos (Fage, et al., 2021; Fagen, et al., 2017; Hassan, et al., 2021).

\subsection{Sobre a relação inversa entre a presença de genes de resistência e CRISPR-Cas funcional/ modificação de restrição (RM-Restriction Modification)}

Tratando-se do gênero Enterococcus, a espécie E. faecalis é uma das mais estudadas e bem descritas na literatura. E.faecalis possui uma vasta capacidade de aquisição de genes de resistência e virulência mediante transferência horizontal mediada por plasmídeos responsivos a (PRPs- Pheromone responsive plasmids)(Hirt, et al., 2018). Os PRPs são plasmídeos ativados pela excreção de feromônios peptídicos que, de uma maneira geral, são secretados constitutivamente pelas bactérias. No momento em que a bactéria contendo o plasmídeo(doador) entra em contato com a outra que não possui o plasmídeo e secreta o feromônio(receptor) ocorre a transferência horizontal de genes que podem conferir resistência e aumento da virulência as bactérias receptoras (Sterling, et al., 2020).

Contudo, com o desenvolvimento da pesquisa com respeito a capacidade de E.faecalis de receber elementos genéticos móveis (MGE-Mobile genetics elements), notou-se que tal fenômeno se deve ao fato de que as cepas mais resistentes e virulentas são imunocomprometidas, visto que não possuem o CRISPR-Cas funcional, que é uma barreira endógena contra aquisição de MGEs, demonstrando assim, que o uso indevido e exacerbado de antibióticos selecionam cepas imunocomprometidas e, portanto, com maior capacidade de adquirir genes de resistência e virulência (Palmer \& Gilmore, 2010).

Corroborando essas observações, outros estudos demonstram a existência de sistema coadjuvante na proteção da célula bacteriana contra a aquisição de MGEs, a modificação de restrição(RM). Esta, por sua vez, consiste em alterações no DNA 
bacteriano ocasionado por metiltransferases que metilam o DNA bacteriano com citosina (C) ou adenina (A), diferenciando, assim, o DNA próprio do não-próprio, fazendo com que uma endonuclease promova a clivagem do DNA não-próprio, que pode coincidir com o dos MGEs (Huo, et al., 2015).

Interessantemente, como visto em estudos recentes, observou-se que a RM e CRISPR-Cas podem atuar sinergicamente, aumentando a proteção da célula bacteriana contra MGEs, favorecendo assim a hipótese de que as bactérias multirresistentes são imunocomprometidas(Price, et al., 2016). Dado isto, uma equipe de pesquisa brasileira buscou elucidar a relação entre a presença de CRISPR com a presença de genes de resistência e virulência. Neste estudo, notou-se que a maior parte dos CRISPR encontrados estavam em isolados de E.faecalis no qual se observou que as cepas sem CRISPR apresentavam mais genes de resistência e virulência, como: VanA, hyl e esp, respectivamente (Santos, et al., 2020). Outros estudos apresentaram resultados semelhantes, evidenciando essa mesma relação inversa entre CRISPR-Cas funcional e resistência a antibióticos (Tong, et al., 2017). Este mesmo fenômeno pode ser observado em outros gêneros e espécies (ex: Klebsiella pneumoniae e Shigella sp.,) como têm demonstrado estudos recentes. Surpreendentemente, vários estudos com bactérias de diversas espécies têm demonstrado que na ausência de CRISPR-Cas funcional, a célula bacteriana fica mais suscetível a aquisição de MGEs, expandindo assim, o genoma com genes de resistência e virulência (Mackow, et al., 2019; Wang, et al., 2020; Chen, et al., 2019).

\subsection{Impacto do uso de plasmídeos conjugativos contendo CRISPR-Cas sobre a aquisição de elementos genéticos móveis (MGE)}

A partir das descobertas descritas acima--de que a célula bacteriana multirresistente a antibióticos é na verdade uma célula imunocomprometida--alguns pesquisadores analisaram a capacidade de E.faecalis poder receber o plasmídeo exógeno contendo CRISPR-Cas, com o intuito de aferir a possibilidade dela receber o plasmídeo CRISPR-Cas sem ser letal a célula a qual denominou-se "tolerância" de E.faecalis ao plasmídeo com CRISPR-Cas. Surpreendentemente, ficou demonstrado que E.faecalis é capaz de receber CRISPR conjugativo sem dano a sobrevida da célula, porém, com o aumento da quantidade de Cas9, observou-se aumento da letalidade e resistência a bacteriófagos(Hullahalli, et al., 2018).

Um outro estudo, procurou-se investigar o impacto da alteração das condições(proporção doador/receptor, acasalamento planctônico/biofilme, presença/ausência de $\operatorname{Cas} 9$ ) no rendimento da aquisição de plasmídeos, no qual notou-se que a presença de Cas 9 em E. faecalis T11RF(tipo selvagem) - que expressa CRISPR3-Cas -- considerada a principal barreira protetora antiPRP em E.faecalis-- resistiu bem como barreira contra a aquisição de plasmídeos pAM 714, diferindo assim das cepas com deleção de Cas9 (T11RFAcas9), que apresentaram maior tolerância a aquisição do plasmídeo, visto que não possui barreiras contra aquisição de plasmídeos invasores. Surpreendentemente, nesse mesmo estudo, os autores realizaram a colonização in vivo no intestino de um camundongo disbiotico e puderam perceber que, novamente, as cepas T11RF $4 \operatorname{cas} 9 \operatorname{com}$ deleção de $\operatorname{cas} 9$ apresentaram uma maior quantidade de transconjugantes contendo o plasmídeo pAM714, demonstrando assim que CRISPRCas é uma barreira eficiente contra aquisição de EGMs (Price, et al., 2019).

Corroborando os resultados, outro estudo demonstrou a eficiência do uso de antimicrobianos CRISPR-Cas in vitro e in vivo, na redução da ocorrência de resistência a determinados antibióticos. Os pesquisadores notaram também que as cepas de E.faecalis doadores, contendo antimicrobianos CRISPR-Cas, desenvolveram "imunidade" contra a absorção de traços de resistência a antibióticos in vivo (Rodrigues, et al., 2019).

Ainda, outros autores propuseram um novo método de edição de genoma baseado em CRISPR-Cas para E.faecium, cujas informações a respeito deste patógeno são escassas. Neste novo modelo, os pesquisadores fizeram apenas um teste para a deleção de $L a c L$, que codifica uma subunidade da $\beta$-galactosidase, cuja presença pode ser facilmente aferida com utilização Xgal para triagem. As colônias brancas foram negativas para $L a c L$ e as azuis positivas. $\mathrm{O}$ sistema de edição em si, consistiu em 2 vectores básicos: pVPL3004 (codificando Cas9, tracRNA e um marcador de seleção de eritromicina ) e pVDM1001 (CRISPR, 
DNA molde com a mutação desejada e um marcador de espectinomicina). Para aprimorar o processo e prevenir a letalidade às células bacterianas, os pesquisadores decidiram inserir no cromossomo de E.faecium um modelo de recombinação homóloga (HR), juntamente com o marcador fluorescente $g f p$, que flanqueando em dois lugares distintos do gene $m s r C$, que codifica resistência intrínseca à macrolídeos. Para aferição da funcionalidade do sistema, transformou-se E.faecium com: água deionizada como um "background", vetor vazio, vetor contendo CRISPR-Cas direcionado a LacL e um vetor contendo HR e CRISPR-Cas direcionado à $L a c L$. Interessantemente, notou-se que as colônias contendo apenas água deionizada (70) estavam em maior número em relação às que foram transformadas com CRISPR direcionado a LacL (68), demonstrando assim, uma possível letalidade de CRISPR na célula bacteriana. Este resultado foi corroborado pelo maior número de colônias contendo o modelo HR (80), indicando que, possivelmente, HR protegeu as células da letalidade gerada pela quebra da fita dupla efetuada por CRISPR. Esses achados laboratoriais indicam um possível avanço na formulação de sistemas de edição genômica para E.faecium, concomitantemente, para o uso de plasmídeos direcionados contra genes de resistência e virulência (De Maat, et al., 2019).

\section{Conclusão}

Enterococcus é um gênero bacteriano que abriga duas espécies oportunistas comensais de importância clínica e de saúde pública global: E.faecalis e E.faecium, que estão diretamente relacionadas à infecções relacionadas à assistência à saúde (IRAS).

Embora esforços venham sendo realizados no sentido de reduzir o uso irracional de antibióticos, que resulta na seleção de linhagens cada vez mais resistentes, existe a necessidade do desenvolvimento de novas abordagens terapêuticas, especialmente aquelas com menor pressão seletiva nas bactérias. Neste sentido, começaram a surgir reformulações e inovações de antibióticos de próxima geração, dentre essas abordagens, o uso de CRISPR-Cas em sistemas conjugativos demonstra ser uma "ferramenta" oportuna e promissora.

É crescente o número de estudos que primam elucidar a "mecanística" antimicrobiana por trás do sistema CRISPR-Cas, e como esta ferramenta interage de modo intra e inter espécies bacterianas.

A descoberta que bactérias multirresistentes apresentam baixa incidência de CRISPR funcional e modificação de restrição (MR) é interessante no tocante ao uso deste método nesses alvos. Por outro lado, a despeito dessa ausência de CRISPR, observa-se que E. faecalis apresenta tolerância em receber plasmídeos carreando CRISPR-Cas, o que sugere possibilidade do uso desse sistema em plasmídeos conjugativos.

Vale destacar que os dados discutidos nesta revisão fortemente sugerem a eficácia do uso de CRISPR-Cas contra a aquisição de elementos genéticos móveis (EGM), in vitro e in vivo em E.faecalis.

Nota-se o potencial do uso CRISPR-Cas em E.faecalis e E.faecium para o controle da disseminação de MGEs carreadores de traços de resistência aos antibióticos e virulência, propiciando, assim, uma nova abordagem terapêutica no controle da disseminação de patógenos multirresistentes (Figura 1).

Ainda vale pontuar entre os desafios desta tecnologia, a necessidade de desenvolvimento de um sistema de entrega adequado assim como a otimização da disseminação de CRISPR-Cas nas comunidades microbianas que deve ser melhor compreendida em estudos futuros a fim de entender, de forma mais detalhada os riscos e o potencial desta tecnologia em sua totalidade. Além disso, não menos importante, este assunto já necessita ser debatido nas esferas regulatórias, a fim de elaborar as normas para a utilização deste sistema no desenvolvimento de ensaios clínicos, regulação, fiscalização e de vigilância com intuito de garantir o uso seguro e eficaz desta expoente tecnologia.

O sistema CRISPR-Cas atua como uma espécie de "sistema imunológico em bactérias" reconhecendo sequências de DNA específicas em genes alvo. As enzimas com função endonucleases (em amarelo), por meio de uma sequência de RNA ou 
DNA guia (em laranja) reconhecem e clivam o DNA em regiões de homologia e emparelhamento com a guia, o que impede/reduz a expressão dos genes alvos de resistência aos antibióticos ou fatores de virulência.

Figura 1 - Resumo gráfico do modelo de atuação do sistema CRISPR-Cas proposto em Enterococcus sp.

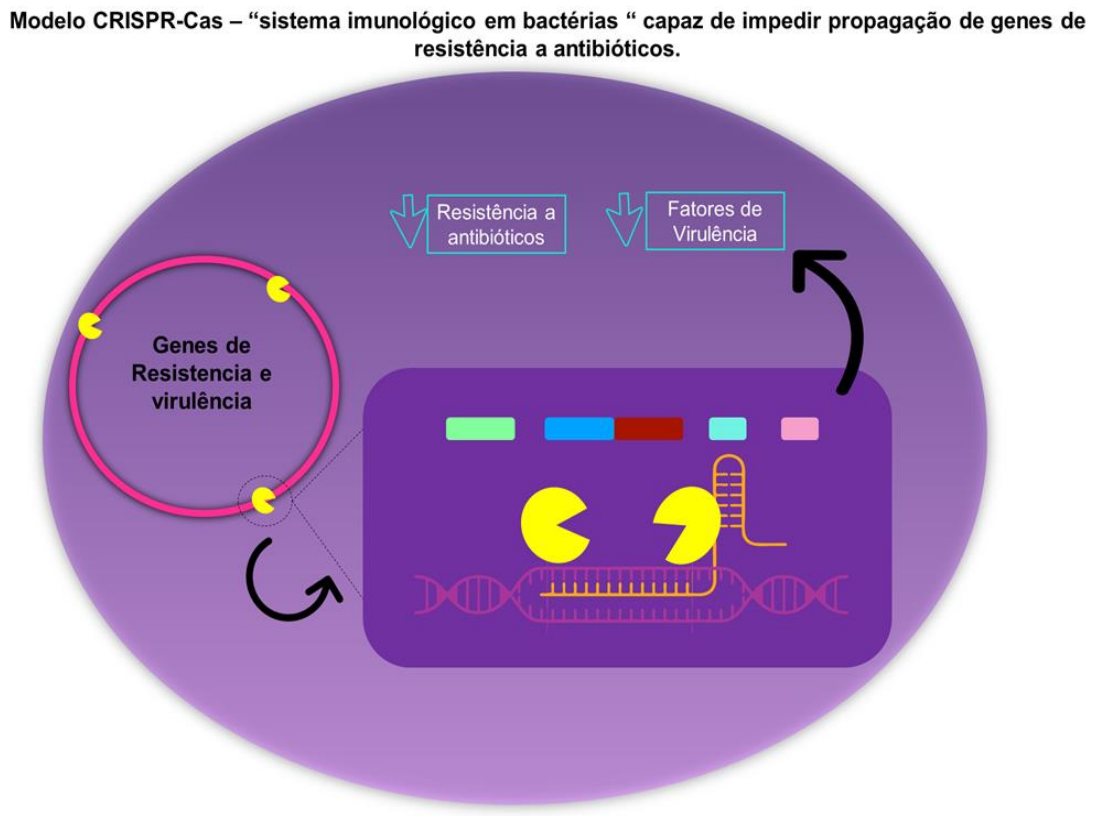

Fonte: Autores.

\section{Agradecimentos}

A Universidade de Brasília, ao laboratório de Análises Clínicas, ao Laboratório de Microbiologia e Imunologia Clínica (LabMIC) e ao grupo do projeto Superbug.UnB.

\section{Conflito de interesse}

Os autores afirmam não haver conflito de interesses.

\section{Referências}

Ahmed, W.; Hafeez, M. A.; Ahmad, R.; Mahmood, S. CRISPR-Cas system in regulation of immunity and virulence of bacterial pathogens. Gene Reports, [S.L.], v. 13, p. 151-157, dez. 2018. Elsevier BV. http://dx.doi.org/10.1016/j.genrep.2018.10.004

Alemayehu, T., \& Hailemariam, M. (2020). Prevalence of vancomycin-resistant enterococcus in Africa in one health approach: a systematic review and metaanalysis. Scientific reports, 10(1), 20542. https://doi.org/10.1038/s41598-020-77696-6

Bender, E. A., de Freitas, A. L., Reiter, K. C., Lutz, L., \& Barth, A. L. (2009). Identification, antimicrobial resistance and genotypic characterization of Enterococcus spp. isolated in Porto Alegre, Brazil. Brazilian journal of microbiology: [publication of the Brazilian Society for Microbiology], 40(3), 693-700. https://doi.org/10.1590/S1517-838220090003000035

CDC. (2019). Antibiotic resistance threats in the United States, 2019. antibiotic resistance threats in the united states. https://doi.org/10.15620/cdc:82532

Chen, S., Liu, H., Liang, W., Hong, L., Zhang, B., Huang, L., Guo, X., \& Duan, G. (2019). Insertion sequences in the CRISPR-Cas system regulate horizontal antimicrobial resistance gene transfer in Shigella strains. International journal of antimicrobial agents, 53(2), 109-115. https://doi.org/10.1016/j.ijantimicag.2018.09.020

Fuente-Nunez, C., Torres, M. D., Mojica, F. J., \& Lu, T. K. (2017). Next-generation precision antimicrobials: towards personalized treatment of infectious diseases. Current opinion in microbiology, 37, 95-102. https://doi.org/10.1016/j.mib.2017.05.014 
Maat, V., Stege, P. B., Dedden, M., Hamer, M., van Pijkeren, J. P., Willems, R., \& van Schaik, W. (2019). CRISPR-Cas9-mediated genome editing in vancomycin-resistant Enterococcus faecium. FEMS microbiology letters, 366(22), fnz256. https://doi.org/10.1093/femsle/fnz256

Dong, H., Xiang, H., Mu, D., Wang, D., \& Wang, T. (2019). Exploiting a conjugative CRISPR/Cas9 system to eliminate plasmid harbouring the mcr-1 gene from Escherichia coli. International journal of antimicrobial agents, 53(1), 1-8. https://doi.org/10.1016/j.ijantimicag.2018.09.017

Dos Santos, B. A., de Oliveira, J., Parmanhani-da-Silva, B. M., Ribeiro, R. L., Teixeira, L. M., \& Neves, F. (2020). CRISPR elements and their association with antimicrobial resistance and virulence genes among vancomycin-resistant and vancomycin-susceptible enterococci recovered from human and food sources. Infection, genetics and evolution: journal of molecular epidemiology and evolutionary genetics in infectious diseases, 80, 104183. https://doi.org/10.1016/j.meegid.2020.104183

Fage, C., Lemire, N., \& Moineau, S. (2021). Delivery of CRISPR-Cas systems using phage-based vectors. Current opinion in biotechnology, 68, 174-180. https://doi.org/10.1016/j.copbio.2020.11.012

Fagen, J. R.; Collias, D.; Singh, A. K.; Beisel, C. L. Advancing the design and delivery of CRISPR antimicrobials. Current Opinion In Biomedical Engineering, [S.L.], v. 4, p. 57-64, dez. 2017. Elsevier BV. http://dx.doi.org/10.1016/j.cobme.2017.10.001.

Gholizadeh, P., Köse, Ş., Dao, S., Ganbarov, K., Tanomand, A., Dal, T., Aghazadeh, M., Ghotaslou, R., Ahangarzadeh Rezaee, M., Yousefi, B., \& Samadi Kafil, H. (2020). How CRISPR-Cas System Could Be Used to Combat Antimicrobial Resistance. Infection and drug resistance, 13, 1111-1121. https://doi.org/10.2147/IDR.S247271

Gilmore, M. S., Clewell, D. B., Ike, Y., \& Shankar, N. (Eds.). (2014). Enterococci: From Commensals to Leading Causes of Drug Resistant Infection. Massachusetts Eye and Ear Infirmary.

Graham, C. E., Cruz, M. R., Garsin, D. A., \& Lorenz, M. C. (2017). Enterococcus faecalis bacteriocin EntV inhibits hyphal morphogenesis, biofilm formation, and virulence of Candida albicans. Proceedings of the National Academy of Sciences of the United States of America, 114(17), 4507-4512. https://doi.org/10.1073/pnas.1620432114

Gupta, D., Bhattacharjee, O., Mandal, D., Sen, M. K., Dey, D., Dasgupta, A., Kazi, T. A., Gupta, R., Sinharoy, S., Acharya, K., Chattopadhyay, D., Ravichandiran, V., Roy, S., \& Ghosh, D. (2019). CRISPR-Cas9 system: A new-fangled dawn in gene editing. Life sciences, 232 , 116636. https://doi.org/10.1016/j.lfs.2019.116636

Hassan, A. Y., Lin, J. T., Ricker, N., \& Anany, H. (2021). The Age of Phage: Friend or Foe in the New Dawn of Therapeutic and Biocontrol Applications? Pharmaceuticals (Basel, Switzerland), 14(3), 199. https://doi.org/10.3390/ph14030199

Hirt, H., Greenwood-Quaintance, K. E., Karau, M. J., Till, L. M., Kashyap, P. C., Patel, R., \& Dunny, G. M. (2018). Enterococcus faecalis Sex Pheromone cCF10 Enhances Conjugative Plasmid Transfer In Vivo. mBio, 9(1), e00037-18. https://doi.org/10.1128/mBio.00037-18

Hullahalli, K., Rodrigues, M., Nguyen, U. T., \& Palmer, K. (2018). An Attenuated CRISPR-Cas System in Enterococcus faecalis Permits DNA Acquisition. mBio, 9(3), e00414-18. https://doi.org/10.1128/mBio.00414-18

Huo, W., Adams, H. M., Zhang, M. Q., \& Palmer, K. L. (2015). Genome Modification in Enterococcus faecalis OG1RF Assessed by Bisulfite Sequencing and Single-Molecule Real-Time Sequencing. Journal of bacteriology, 197(11), 1939-1951. https://doi.org/10.1128/JB.00130-15

Jabbari Shiadeh, S. M., Pormohammad, A., Hashemi, A., \& Lak, P. (2019). Global prevalence of antibiotic resistance in blood-isolated Enterococcus faecalis and Enterococcus faecium: a systematic review and meta-analysis. Infection and drug resistance, 12, 2713-2725. https://doi.org/10.2147/IDR.S206084

Jannati, E., Amirmozaffari, N., Saadatmand, S., \& Arzanlou, M. (2020). Faecal carriage of high-level aminoglycoside-resistant and ampicillin-resistant Enterococcus species in healthy Iranian children. Journal of global antimicrobial resistance, 20, 135-144. https://doi.org/10.1016/j.jgar.2019.06.022

Kiga, K., Tan, X. E., Ibarra-Chávez, R., Watanabe, S., Aiba, Y., Sato'o, Y., Li, F. Y., Sasahara, T., Cui, B., Kawauchi, M., Boonsiri, T., Thitiananpakorn, K., Taki, Y., Azam, A. H., Suzuki, M., Penadés, J. R., \& Cui, L. (2020). Development of CRISPR-Cas13a-based antimicrobials capable of sequence-specific killing of target bacteria. Nature communications, 11(1), 2934. https://doi.org/10.1038/s41467-020-16731-6

Kilbas, I., \& Ciftci, I. H. (2018). Antimicrobial resistance of Enterococcus isolates in Turkey: A meta-analysis of current studies. Journal of global antimicrobial resistance, 12, 26-30. https://doi.org/10.1016/j.jgar.2017.08.012

Mackow, N. A., Shen, J., Adnan, M., Khan, A. S., Fries, B. C., \& Diago-Navarro, E. (2019). CRISPR-Cas influences the acquisition of antibiotic resistance in Klebsiella pneumoniae. PloS one, 14(11), e0225131. https://doi.org/10.1371/journal.pone.0225131

Melese, A., Genet, C., \& Andualem, T. (2020). Prevalence of Vancomycin resistant enterococci (VRE) in Ethiopia: a systematic review and meta-analysis. BMC infectious diseases, 20(1), 124. https://doi.org/10.1186/s12879-020-4833-2

Palmer, K. L., \& Gilmore, M. S. (2010). Multidrug-resistant enterococci lack CRISPR-cas. mBio, 1(4), e00227-10. https://doi.org/10.1128/mBio.00227-10

Price, V. J., Huo, W., Sharifi, A., \& Palmer, K. L. (2016). CRISPR-Cas and Restriction-Modification Act Additively against Conjugative Antibiotic Resistance Plasmid Transfer in Enterococcus faecalis. mSphere, 1(3), e00064-16. https://doi.org/10.1128/mSphere.00064-16

Price, V. J., McBride, S. W., Hullahalli, K., Chatterjee, A., Duerkop, B. A., \& Palmer, K. L. (2019). Enterococcus faecalis CRISPR-Cas Is a Robust Barrier to Conjugative Antibiotic Resistance Dissemination in the Murine Intestine. mSphere, 4(4), e00464-19. https://doi.org/10.1128/mSphere.00464-19

Rodrigues, M., McBride, S. W., Hullahalli, K., Palmer, K. L., \& Duerkop, B. A. (2019). Conjugative Delivery of CRISPR-Cas9 for the Selective Depletion of Antibiotic-Resistant Enterococci. Antimicrobial agents and chemotherapy, 63(11), e01454-19. https://doi.org/10.1128/AAC.01454-19 
Research, Society and Development, v. 11, n. 3, e10311326179, 2022

(CC BY 4.0) | ISSN 2525-3409 | DOI: http://dx.doi.org/10.33448/rsd-v11i3.26179

Sharifzadeh Peyvasti, V., Mohabati Mobarez, A., Shahcheraghi, F., Khoramabadi, N., Razaz Rahmati, N., \& Hosseini Doust, R. (2020). High-level aminoglycoside resistance and distribution of aminoglycoside resistance genes among Enterococcus spp. clinical isolates in Tehran, Iran. Journal of global antimicrobial resistance, 20,318-323. https://doi.org/10.1016/j.jgar.2019.08.008

Sterling, A. J., Snelling, W. J., Naughton, P. J., Ternan, N. G., \& Dooley, J. (2020). Competent but complex communication: The phenomena of pheromoneresponsive plasmids. PLoS pathogens, 16(4), e1008310. https://doi.org/10.1371/journal.ppat.1008310

Sully, E. K., \& Geller, B. L. (2016). Antisense antimicrobial therapeutics. Current opinion in microbiology, 33, 47-55. https://doi.org/10.1016/j.mib.2016.05.017

Tagliaferri, T. L., Guimarães, N. R., Pereira, M., Vilela, L., Horz, H. P., Dos Santos, S. G., \& Mendes, T. (2020). Exploring the Potential of CRISPR-Cas9 Under Challenging Conditions: Facing High-Copy Plasmids and Counteracting Beta-Lactam Resistance in Clinical Strains of Enterobacteriaceae. Frontiers in microbiology, 11, 578. https://doi.org/10.3389/fmicb.2020.00578

Tong, Z., Du, Y., Ling, J., Huang, L., \& Ma, J. (2017). Relevance of the clustered regularly interspaced short palindromic repeats of Enterococcus faecalis strains isolated from retreatment root canals on periapical lesions, resistance to irrigants and biofilms. Experimental and therapeutic medicine, 14(6), 54915496. https://doi.org/10.3892/etm.2017.5205

Vogkou, C. T., Vlachogiannis, N. I., Palaiodimos, L., \& Kousoulis, A. A. (2016). The causative agents in infective endocarditis: a systematic review comprising 33,214 cases. European journal of clinical microbiology \& infectious diseases : official publication of the European Society of Clinical Microbiology, 35(8), 1227-1245. https://doi.org/10.1007/s10096-016-2660-6

Wada, Y., Harun, A. B., Yean, C. Y., \& Zaidah, A. R. (2020). Vancomycin-Resistant Enterococci (VRE) in Nigeria: The First Systematic Review and MetaAnalysis. Antibiotics (Basel, Switzerland), 9(9), 565. https://doi.org/10.3390/antibiotics9090565

Wang, G., Song, G., \& Xu, Y. (2020). Association of CRISPR/Cas System with the Drug Resistance in Klebsiella pneumoniae. Infection and drug resistance, 13, 1929-1935. https://doi.org/10.2147/IDR.S253380

Wojciechowska, M., Równicki, M., Mieczkowski, A., Miszkiewicz, J., \& Trylska, J. (2020). Antibacterial Peptide Nucleic Acids-Facts and Perspectives. Molecules (Basel, Switzerland), 25(3), 559. https://doi.org/10.3390/molecules25030559

Wu, Z. Y., Huang, Y. T., Chao, W. C., Ho, S. P., Cheng, J. F., \& Liu, P. Y. (2019). Reversal of carbapenem-resistance in Shewanella algae by CRISPR/Cas9 genome editing. Journal of advanced research, 18, 61-69. https://doi.org/10.1016/j.jare.2019.01.011

Yoong, P., Schuch, R., Nelson, D., \& Fischetti, V. A. (2004). Identification of a broadly active phage lytic enzyme with lethal activity against antibiotic-resistant Enterococcus faecalis and Enterococcus faecium. Journal of bacteriology, 186(14), 4808-4812. https://doi.org/10.1128/JB.186.14.4808-4812.2004. 